\title{
DIMENSI RELATIONSHIP MARKETING TERHADAP LOYALITAS PELANGGAN INDIHOME TRIPLE PLAY PT TELKOM
}

\author{
Fitriani Latief 1 ) \\ Email: fitri@stienobel-indonesia.ac.id \\ ${ }^{1}$ Dosen Prodi Manajemen, STIE Nobel Indonesia Makassar
}

(Diterima: 25 Januari 2019; direvisi: 27 Februari 2019; dipublikasikan: 08 April 2019 )

\begin{abstract}
Abstrak:Penelitian ini bertujuan menganalisis dimensi relationship marketing yang terdiri dari komunikasi, kepercayaan, empati dan komitmen terhadap loyalitas pelanggan IndiHome Triple Play PT Telkom Makassar. Variabel yang digunakan dalam penelitian ini yaitu komunikasi (X1), kepercayaan (X2), empati (X3), komitmen (X4) dan loyalitas pelanggan (Y). Teknik sampel yang digunakan adalah judgment sampling yaitu sebanyak 90 orang pelanggan IndiHome Triple Play PT Telkom Akses Regional VII Makassar yang sudah berlangganan minimal 3 bulan. Metode pengujian data menggunakan analisis regresi berganda dengan bantuan SPSS versi 23.00. Berdasarkan hasil pengujian data diperoleh bahwa komunikasi, kepercayaan, empati dan komitmen berpengaruh positif dan signifikan terhadap loyalitas pelanggan IndiHome Triple Play PT Telkom Akses Regional VII Makassar.
\end{abstract}

Kata kunci: Komunikasi, Kepercayaan, Empati, Komitmen, Loyalitas Pelanggan.

\begin{abstract}
This study aims to analyze dimension relationship marketing consisting of communication, trust, empathy and commitment on customer loyalty. The variables used in this study are communication (X1), trust (X2), empathy (X3), commitment (X4) and customer loyalty (Y). The sample technique used with judgment sampling so that 90 samples customer IndiHome Triple Play PT Telkom Akses Regional VII Makassar who have subscribed for at least 3 months. Data testing method uses multiple regression analysis with the help of SPSS version 23.00. Based on the results of testing the data obtained that the awareness of communication, trust, empathy and commitment have a positive and significant effect on customer royalty IndiHome Triple Play PT Telkom Akses Regional VII Makassar.
\end{abstract}

Keywords: Communication, Trust, Empathy, Commitment, Customer Loyalty.

\section{PENDAHULUAN}

Perkembangan globalisasi mengakibatkan kebutuhan masyarakat Indonesia saat ini tidak dapat dipisahkan dari teknologi digital, khususnya internet kecepatan tinggi. Peningkatan pengguna telepon seluler dari semua kalangan menuntut perusahaan yang bergerak sebagai penyedia jasa (service provider) bersaing pesat dan semakin berorientasi kepada pelanggan.

IndiHome Triple Play merupakan salah satu inovasi produk PT Telkom Indonesia (Persero) Tbk yang menyediakan akses internet kecepatan tinggi hingga 100 Mbps menggunakan teknologi fiber optic dan memiliki layanan televisi interakrif dengan beragam konten hiburan keluarga yang edukatif.

Oleh karena itu, IndiHome Triple Play merupakan produk PT Telkom Yang tercatat memiliki lebih dari 3 juta pelanggan yang terbesar diseluruh Indoenesia sehingga meraih Top Brand untuk kategori Internet Service Provider Fixed Terbaik. (Sumber:https://nusantaranews.com, Februari 2018)

Dari pencapaian ini, PT Telkom perlu melakukan berbagai upaya untuk mempertahankan pelanggan agar tetap loyal kepada perusahaan dan tidak beralih ke pesaing yang ada. 
Loyalitas pelanggan adalah suatu komitmen yang mendalam untuk berlangganan atau membeli kembali suatu produk atau jasa secara konsisten di masa yang akan datang. Oleh karena itu, untuk mendapatkan loyalitas atau kesetiaan konsumen perusahaan perlu strategi pemasaran yang tepat dan kompleks.

Banyak cara yang dapat dilakukan oleh suatu perusahaan untuk membangun loyalitas pelanggan. Salah satu caranya adalah membina dan memahami kebutuhan dan keinginan pelanggan melalui suatu strategi pemasaran yang disebut relationship marketing. Relationship marketing yaitu suatu aplikasi yang diterapkan secara konsisten untuk mendapatkan pengetahuan up to date dari seorang konsumen untuk mendesain produk dan jasa dimana hal ini dikomunikasikan dengan timbal balik untuk mengembangkan hubungan jangka panjang dan berkelanjutan yang saling menguntungkan.

$$
\text { Menurut Tandjung (2004:89), }
$$

relationship marketing adalah pertumbuhan, pengembangan dan pemeliharaan dalam jangka panjang yang menimbulkan hubungan biaya efektif dengan pelanggan, pemasok, karyawan dan partner-partner lain yang saling menguntungkan.

Lebih lanjut, Tandjung (2004:91), menerangkan ada empat dimensi relationship marketing yang digunakan perusahaan dalam strategi pemasarannya yaitu Ikatan (Bonding), Empati (Empathy), Timbal balik (Reciprocity) dan Kepercayaan (Trust). Dimensi tersebut harus diperhatikan oleh perusahaan agar strategi Relationship marketing yang diterapkan berjalan dengan baik dan sesuai target yang diinginkan perusahaan.

Hasil penelitian Murti (2013) menemukan bahwa kepercayaan berpengaruh positif dan signifikan terhadap loyalitas pelanggan. Hasil ini sejalan dengan hasil penelitian Jushermi dan Asriadi (2013) yang menemukan bahwa kepercayaan positif dan signifikan terhadap loyalitas pelanggan.

Hasil lain yang ditemukan oleh Jushermi dan Asriadi (2013) yakni komunikasi dan empati tidak berpengaruh signifikan terhadap loyalitas pelanggan. Lain halnya dengan hasil penelitian yang ditemukan oleh Ellena (2013) yang menemukan bahwa kepercayaan, komitmen dan komunikasi berpengaruh positif dan signifikan terhadap loyalitas konsumen.

Berdasarkan pemaparan di atas, maka dilakukan penelitian dengan tujuan untuk mengetahui dan menganalisis pengaruh relathionship marketing terhadap loyalitas pelanggan.

\section{TINJAUAN TEORI}

\section{Loyalitas Pelanggan}

Tjiptono (2008:387), loyalitas merupakan situasi dimana konsumen bersikap positif terhadap produk/produsen (penyedia jasa) dan disertai pola pembelian ulang yang konsisten. Sedangkan menurut Hurriyati (2015), loyalitas adalah komitmen pelanggan bertahan secara mendalam untuk berlangganan kembali atau melakukan pembelian ulang produk/jasa terpilih secara konsisten dimasa yang akan datang, meskipun pengaruh situasi dan usaha-usaha pemasaran mempunyai potensi untuk menyebabkan perubahan perilaku.

\section{Dimensi Relationship Marketing}

Berbagai studi dan literatur mengenai relationship marketing cenderung mengarah pada konteks B2B (business to business). Relationship marketing dianggap lebih penting dalam konteks industri business to business dibandingkan dengan konteks konsumen individu, sehingga penelitian lebih banyak dilakukan dalam konteks B2B, bahkan dalamindustri tertentu saja. Oleh sebab itu, dimensi pengukuran relationship marketing dalam konteks B2C (bussines to customer).

Abdullah dan Kanyan (2013), melakukan studi dalam industri foodservice untuk menentukan dimensi yang relevan untuk konteks B2C, dan hasil analisis menunjukkan empat dimensi yang terdiri dari :

1. Communication (Komunikasi), menekankan pentingnya berkomunikasi dengan cara yang mudah dimengerti, memberikan penjelasan yang jelas, memberikan saran-saran yang membantu konsumen, dan mengetahui cara menghargai konsumen. Dimensi ini juga menekankan pentingnya penilaian dan penggunaan umpan balik dari konsumen dalam meningkatkan pemberian layanan serta secara berkala menanyakan opini dan saran dari konsumen.

2. Trust (kepercayaan) adalah kesediaan konsumen untuk dapat memiliki rasa keyakinan terhadap suatu perusahaan. Setiap partner dapat mengakibatkan kemungkinan rugi, maka ada perlunya untuk menunjukkan perhatian sebagai tanda memelihara suatu kepercayaan (Herdian dan Wirastuti, 2013). Pentingnya kepercayaan konsumen terhadap layanan yang diberikan. Dimensi ini berkaitan 
dengan kemampuan penyedia layanan dalam memenuhi kewajibannya dan menunjukkan respect kepada konsumen.

3. Empathy (empati), mengacu pada kemampuan personil atau staf untuk menunjukkan simpati ketika berhadapan dengan konsumen. Penting bagi karyawan untuk menampilkan perilaku yang ramah, sopan, dan menyenangkan dalam memberikan pelayanan untuk menumbuhkan keyakinan konsumen.

4. Commitment (komitmen), mendeskripsikan komitmen dan usaha perusahaan dalam menyediakan layanan yang terbaik untuk mewujudkan dan mempertahankan hubungan dengan konsumen dalam jangka panjang. Komitmen menekankan kemampuan perusahaan menyediakan produk dan jasa yang superior dengan harga yang pantas/masuk akal dan memberikan layanan secara tepat dan benar, serta memenuhi kebutuhan dan keperluan konsumen.

Dalam penelitian in, dimensi relathionship marketing yang digunakan merujuk pada hasil analisis penelitian Abdullah dan Kanyan (2013) bahwa dimensi relathionship marketing yang digunakan yaitu komunikasi, kepercayaan, empati dan komitmen.

\section{METODE}

\section{Pendekatan Penelitian}

Pendekatan penelitian yang digunakan dalam penelitian ini adalah pendekatan deskriptif kuantitatif. Santoso (2012) menjelaskan pendekatan deskriptif kuantitatif merupakan penelitian dengan mendeskripsikan secara sistematis, faktual dan akurat terhadap kondisi dan fenomena yang terjadi berdasarkan data dan informasi yang didapatkan dalam penelitian. Dalam penelitian ini, digunakan metode kuantitatif karena angka, mulai dari pengumpulan data, penafsiran data tersebut, serta menampilkan hasilnya. Selain itu juga akan digunakan tabel, grafik dan diagram.

\section{Populasi dan Sampel}

Populasi penelitian ini adalah pelanggan IndiHome Triple Play PT Telkom Akses Regional VII Makassar. Dalam melakukan penelitian ini sampel yang diambil dari populasi menggunakan judgment sampling, Prosedur dan tehnik pengambilan judgment sampling dengan menggunakan rumus slovin yaitu sebanyak 90 orang pelanggan IndiHome Triple Play PT
Telkom Akses Regional VII Makassar yang sudah berlangganan minimal 3 bulan.

\section{Metode Pengumpulan Data}

Dalam penelitian ini data dikumpulkan dengan menyebar kuesioner kepada wajib pajak badan pada KPP Madya di Makassar. Selanjutnya jawaban dari setiap instrument yang berhasil dikumpulkan melalui proses tabulasi menggunakan skala likert.

\section{Metode Analisis Data}

Untuk menguji hubungan antara variabel independen dan variabel dependen dalam penelitian ini maka dilakukan analisis linier berganda melalui alat analisis program SPSS. Model Persamaan regresi linier berganda adalah sebagai berikut :

$$
\begin{aligned}
\mathrm{Y}= & \alpha+\beta 1 \mathrm{X} 1+\beta 2 \mathrm{X} 2+\beta 3 \mathrm{X} 3+\beta 4 \mathrm{X} 4+\mathrm{e} \\
& \text { Keterangan }: \\
& \mathrm{Y}: \text { Loyalitas pelanggan } \\
& \mathrm{X} 1: \text { Komunikasi } \\
& \mathrm{X} 2: \text { Kepercayaan } \\
& \mathrm{X} 3: \text { Empati } \\
& \mathrm{X} 4: \text { Komitmen } \\
& \alpha: \text { Konstanta. } \\
& \beta: \text { Koefisien Regresi. } \\
& \mathrm{e}: \text { Error. }
\end{aligned}
$$

\section{HASIL DAN PEMBAHASAN Hasil Uji Normalitas}

Dalam penelitian ini untuk menguji normalitas maka digunakan grafik Normal P-P Plot of Regression Standardized Residual untuk melihat model regresi variabel dependen (terikat) dan variabel independen (bebas) apakah mempunyai kontribusi atau tidak.

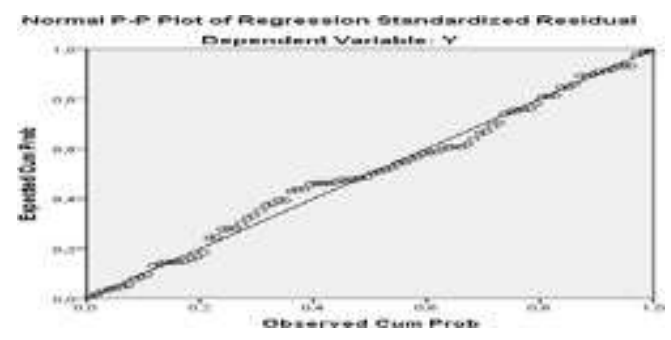

Gambar 1 Hasil Uji Normalitas

Grafik Normal P-P Plot of Regression Standardized Residual sebagaimana tersaji pada gambar 1 terlihat titik-titik menyebar di sekitar garis diagonal, serta arah penyebarannya mengikuti arah garis diagonal. Hal ini menunjukkan bahwa model regresi layak dipakai karena memenuhi asumsi normalitas 


\section{Hasil Uji Multikolinieritas}

Jika ada korelasi yang tinggi di antara variabel-variabel independennya, maka hubungan antara variabel independen terhadap variabel dependennya menjadi terganggu. Untuk menguji multikolinieritas dapat dilihat dari nilai tolerance dan nilai VIF (Variance Inflation Faktor). Jika nilai VIF tidak lebih dari 10 dan nilai tolerance tidak kurang dari 0,1 maka model dapat dikatakan terbebas dari multikolinearitas. Hasil pengujian multikolinieritas dapat dilihat pada tabel 1:

\section{Tabel 1. Hasil Uji Multikolinieritas}

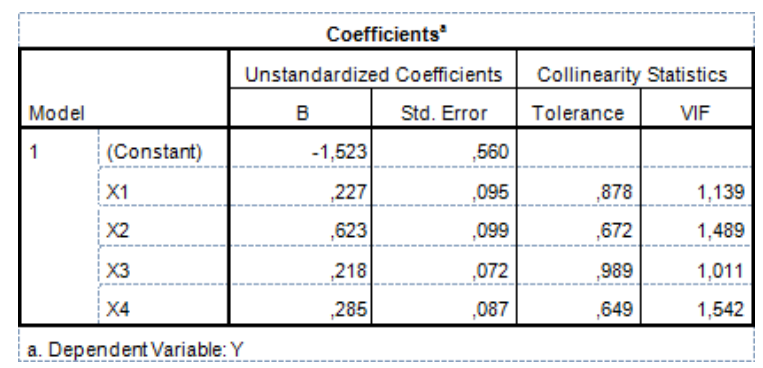

Sumber : Output SPSS, 2019

Hasil uji multikolinearitas yang pada tampilan tabel 2 terlihat bahwa variabel independen memiliki nilai tolerance diatas 0,1 dan VIF lebih kecil dari 10 dan menunjukkan bahwa dalam model persamaan regresi tidak terdapat gejala multikolonearitas sehingga data dapat digunakan dalam penelitian ini.

\section{Hasil Uji Hipotesis}

\section{Uji Koefisien Determinasi (Uji $\left.\mathbf{R}^{\mathbf{2}}\right)$}

Uji koefisien determinasi ini bertujuan untuk mengetahui seberapa besar kemampuan variabel dependen dapat dijelaskan oleh variabel independen. Berikut disajikan hasil uji koefisien determinasi pada tampilan tabel 2 dibawah ini:

\section{Tabel 2. Hasil Uji Koefisien Determinasi}

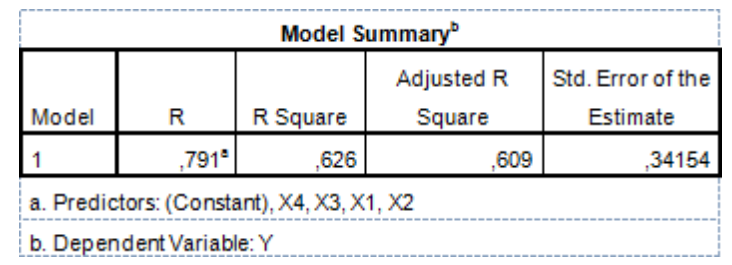

Sumber : Output SPSS, 2019
Berdasarkan output tabel di atas diperoleh nilai $R$ sebesar 0,791 atau $71,90 \%$, nilai ini menunjukkan bahwa variabel independen mempunyai hubungan yang kuat dengan loyalitas pelanggan PT Telkom. Sedangkan nilai koefisien determininasi $\mathrm{R}^{2}$ ( $\mathrm{R}$ square) yang diperoleh adalah 0,626 atau $62,60 \%$. Hal ini menunjukkan bahwa variasi variabel independen yang digunakan dalam model mampu menjelaskan sebesar 62,60\% loyalitas pelanggan IndiHome Triple Play PT Telkom Makassar dipengaruhi oleh kominukasi, kepercayaan, empati dan komitmen, hal ini berarti bahwa $37,40 \%$ loyalitas pelanggan IndiHome Triple Play PT Telkom Makassar dipengaruhi oleh faktor lain yang tidak diteliti dalam penelitian ini.

\section{Hasil Uji Simultan (Uji F)}

Uji ini menggunakan a 5\%. Dengan ketentuan, jika signifikansi dari $\mathrm{F}$ hitung < dari 0,05 maka hipotesis yang diajukan dapat diterima. Hasil pengujiannya ditampilkan pada tabel dibawah ini :

\section{Tabel 3. Hasil Uji Simultan}

\begin{tabular}{|c|c|c|c|c|c|c|}
\hline \multicolumn{7}{|c|}{ AMOVA' } \\
\hline \multicolumn{2}{|c|}{ Model } & Sum of Squares & df & Mean Square & $\mathrm{F}$ & Sig. \\
\hline \multirow[t]{3}{*}{1} & Regression & 16,614 & 4 & 4,154 & 35,607 &, $000^{\circ}$ \\
\hline & Residual & 9,915 & 85 & .117 & & \\
\hline & Total & 26,529 & 89 & & & \\
\hline \multicolumn{7}{|c|}{ a. Dependert Variable:Y } \\
\hline \multicolumn{7}{|c|}{ b. Predictors (Consiant) $\times 4, \times 3, \times 1, \times 2$} \\
\hline
\end{tabular}

\section{Sumber : Output SPSS, 2019}

Tabel 3 menunjukkan bahwa tingat signifikansi lebih kecil dari 0,05, sehingga dapat dikatakan bahwa kominukasi, kepercayaan, empati dan komitmen secara simultan (bersama-sama) mempunyai pengaruh terhadap loyalitas pelanggan IndiHome Triple Play PT Telkom Makassar, dengan probabilitas 0,000 . Karena probabilitas jauh lebih kecil dari nilai signifikan 0,05, maka model regresi dapat digunakan untuk memprediksi loyalitas pelanggan.

\section{Hasil Uji Parsial (Uji t)}


Pada penelitian ini, uji t digunakan untuk menguji apakah hipotesis yang diajukan dalam penelitian ini diterima atau tidak dengan mengetahui apakah variabel independen secara individual memengaruhi variabel dependen. Hasil pengujian uji t pada penelitian ini dapat dilihat pada tabel 4 di bawah ini :

\section{Tabel 4. Hasil Uji Parsial (Uji t)}

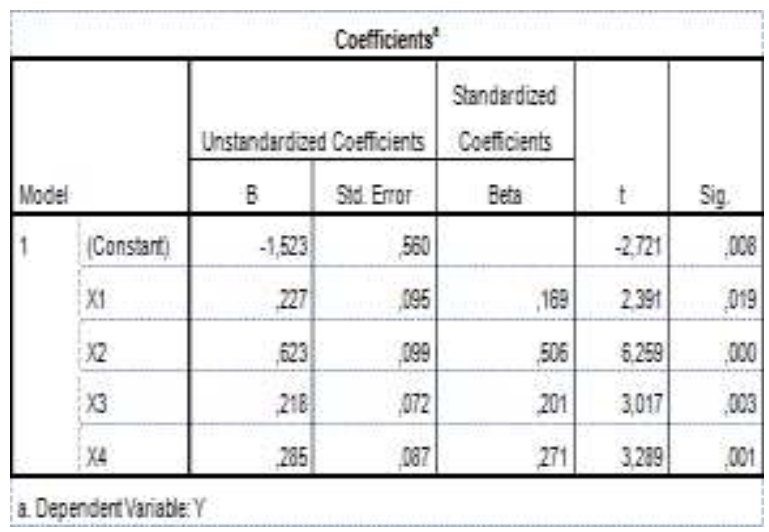

\section{Sumber : Output SPSS, 2019}

Hasil uji regresi linear berganda yang ditampilkan tabel 4 menunjukkan nilai koefisien regresi yang terbentuk pada pengujian ini adalah:

$$
Y=-1,523+0,227 \times 1+0,623 \times 2+0,218 \times 3+0,285 \times 4+e
$$

Persamaan regresi di atas menunjukkan nilai konstanta $-1,523$ dan menyatakan, jika variabel independen (kominukasi, kepercayaan, empati dan komitmen) bernilai nol (0), maka nilai variabel dependen (loyalitas pelanggan) sebesar 1,523 satuan. Koefisien regresi pada variabel komunikasi sebesar 0,227, hasil ini menyatakan jika variabel komunikasi bertambah satu satuan maka variabel loyalitas pelanggan akan meningkat sebesar 0,227 satuan dengan catatan variabel lain dianggap konstan. Koefisien regresi variabel kepercayaan sebesar 0,623 artinya jika kepercayaan bertambah satu satuan maka variabel loyalitas pelanggan akan meningkat sebesar 0,623 satuan dengan catatan variabel lain dianggap konstan. Koefisien regresi empati sebesar 0,218 artinya jika variabel empati bertambah satu satuan maka variabel loyalitas pelanggan akan meningkat sebesar 0,218 satuan dengan catatan variabel lain dianggap konstan. Koefisien regresi komitmen sebesar 0,285 artinya jika variabel komitmen bertambah satu satuan maka variabel loyalitas pelanggan akan meningkat sebesar 0,285 satuan dengan catatan variabel lain dianggap konstan

Berdasarkan hasil uji parsial di atas dapat diketahui pengaruh masing-masing variabel independen yang terdiri atas komunikasi, kepercayaan, empati dan komitmen secara parsial berpengaruh signifikan terhadap variabel dependen yaitu loyalitas pelanggan IndiHome Triple Play PT Telkom Makassar yang akan dijelaskan sebagai berikut :

a) Hipotesis 1 (H1) Komunikasi berpengaruh positif dan signifikan terhadap loyalitas pelanggan pada IndiHome Triple Play PT Telkom Makassar diterima, hal ini diperoleh dari hasil analisis regresi yaitu t-hitung X1= 2,391 dan nilai signifikansi X1 sebesar 0,019 atau berada diantara nilai $0,000<0,05$, maka dapat disimpulkan bahwa komunikasi berpengaruh positif dan signifikan terhadap loyalitas pelanggan IndiHome Triple Play PT Telkom Makassar.

Hasil ini mendukung hasil penelitian Ellena (2013) yang menemukan bahwa komunikasi berpengaruh positif dan signifikan terhadap loyalitas langganan. Komunikasi yang baik yang terjadi antara perusahaan dengan pelanggan akan meningkatkan loyalitas pelanggan.

b) Hipotesis $2(\mathrm{H} 2)$ kepercayaan berpengaruh terhadap loyalitas pelangan IndiHome Triple Play PT Telkom Makassar diterima, hal ini diperoleh dari hasil analisis regresi yaitu $\mathrm{t}$ hitung $\mathrm{X} 2=6,259$ dan nilai signifikansi $\mathrm{X} 2$ sebesar 0,000 atau berada diantara nilai 0,000 $<0,05$, maka dapat disimpulkan bahwa kepercayaan berpengaruh positif dan signifikan terhadap loyalitas pelanggan IndiHome Triple Play PT Telkom Makassar.

Hasil ini sejalan dengan dengan hasil penelitian Jushermi dan Asriadi (2013) yang menemukan bahwa kepercayaan berpengaruh positif dan signifikan terhadap loyalitas pelanggan. Adanya kepercayaan yang tinggi dari pelanggan IndiHome Triple Play PT Telkom Makassar akan meningkatkan loyalitas pelanggan untuk tetap setia berlangganan IndiHome Triple Play.

c) Hipotesis $3(\mathrm{H} 3)$ empati berpengaruh terhadap loyalitas pelanggan IndiHome Triple Play PT 
Telkom Makassar diterima, hal ini diperoleh dari hasil analisis regresi yaitu t-hitung $\mathrm{X} 3=3,017$ dan nilai signifikansi $\mathrm{X} 3$ sebesar 0,003 atau berada diantara nilai $0,000<0,05$, maka dapat disimpulkan bahwa empati berpengaruh positif dan signifikan terhadap loyalitas pelanggan IndiHome Triple Play PT Telkom Makassar.

Hasil ini tidak sejalan dengan hasil penelitian Jushermi dan Asriadi (2013) yang menemukan bahwa empati tidak berpengaruh signifikan terhadap loyalitas pelanggan.

d) Hipotesis 4 (H4) komitmen berpengaruh terhadap loyalitas pelanggan IndiHome Triple Play PT Telkom Makassar diterima, hal ini diperoleh dari hasil analisis regresi yaitu thitung $\mathrm{X} 4=3,289$ dan nilai signifikansi $\mathrm{X} 4$ sebesar 0,001 atau berada diantara nilai 0,000 $<0,05$, maka dapat disimpulkan bahwa komitmen berpengaruh positif dan signifikan terhadap loyalitas pelanngan IndiHome Triple Play PT Telkom Makassar.

Hasil ini mendukung hasil penelitian Ellena (2013) yang menemukan bahwa komitmen berpengaruh positif dan signifikan terhadap loyalitas langganan. Komitmen pelanggan yang tinggi akan meningkatkan loyalitas pelanggan.

\section{KESIMPULAN DAN SARAN}

Hasil penelitian ini menemukan bahwa kominukasi, kepercayaan, empati dan komitmen secara simultan dan parsial mempunyai pengaruh terhadap loyalitas pelanggan IndiHome Triple Play PT Telkom Makassar.

Penelitian ini hanya menggunakan empat variabel yang mempengaruhi loyalitas pelanggan, disarankan kepada peneliti selanjutnya untuk menambah varabel lain yang dapat mempengaruhi loyalitas pelanggan, kemudian disarankan kepada PT Telkom Makassar agar menambah inovasi-inovasi tekhnologi baru sesuai dengan kebutuhan pelanggan agar loyalitas pelanggan dapat meningkat.

\section{DAFTAR RUJUKAN}

Ellena, F. 2013. Analisis Pengaruh Kepercayaan, Komitmen, Komunikasi dan Penanganan Keluhan Terhadap Loyalitas Nasabah. Jurnal Ekonomi Universitas Diponegoro. Semarang.
Firdaus Abdullah, Agnes Kanyan. 2013. Managing The Dimensions of Relationship Marketing in The Food Industry. Jurnal Pengurusan, $37, \mathrm{~h}, 92$

Gina Herdina dan Widyastuti. 2013. Pengaruh Relationship Marketing Terhadap Loyalitas Konsumen pada Nasabah Bank BTPM KCP Sepanjang. Jurnal Ilmu Manajemen vol.1 no.2.

Juhermi dan Ari Asriadi. 2013. Pengaruh Relationship Marketing Terhadap Loyalitas Pengguna Kartu KFC Music Hitter pada KFC Sudirman Pekanbaru. Jurnal Ekonomi Vol.21 no.3 September.

Murti, S.H. 2013. Pengaruh Relationship Marketing Terhadap Loyalitas Pelanggan. Jurnal Unnes (1), ISSN : 255206552.

Ratih Hurriyati. 2015. Bauran Pemasaran dan Loyalitas Konsumen. Bandung : Alfabeta.

Santoso, Singgih. 2012. Analisis SPSS pada Statistik Parametrik. Jakarta : PT. Elex Media Komputindo.

Sugiyono. 2014. Metode Penelitian Bisnis, Alpabeta. Bandung.

Tjiptono, Fandi. 2008. Strategi Pemasaran. Edisi Pertama. Yogyakarta:Andi. 